\title{
Regulation of Formation, Stemness and Therapeutic Resistance of Cancer Stem Cells
}

\author{
Nan Jing ${ }^{1}$, Wei-Qiang Gao ${ }^{1,2 *}$ and Yu-Xiang Fang ${ }^{1 *}$ \\ ' State Key Laboratory of Oncogenes and Related Genes, Renji-Med X Clinical Stem Cell Research Center, Renji Hospital, \\ School of Medicine, Shanghai Jiao Tong University, Shanghai, China, ${ }^{2}$ School of Biomedical Engineering and Med-X \\ Research Institute, Shanghai Jiao Tong University, Shanghai, China
}

Over the past 20 years cancer stem cells (CSCs) have been proposed as key players in the tumorigenesis and progression, which are closely related to the initiation, metastasis and therapeutic resistance of cancer. Evidences have been provided that both genetic and epigenetic factors contribute to the regulation of the formation and stemness maintenance as well as the therapeutic resistance of CSCs via affecting various signal pathways. In addition, the interaction between CSCs and tumor microenvironment has also been revealed to be involved in the above-described processes. With the aim of targeting CSCs to improve treatment outcome, we herein discuss the mechanisms that

OPEN ACCESS

Edited by:

Zuoren Yu,

Tongji University, China

Reviewed by:

Patompon Wongtrakoongate, Mahidol University, Thailand

Lixin Wei,

Second Military Medical University,

China

${ }^{*}$ Correspondence:

Wei-Qiang Gao

gao.weiqiang@sjtu.edu.cn

Yu-Xiang Fang

fyx2003108@sina.com

Specialty section:

This article was submitted to

Stem Cell Research,

a section of the journal

Frontiers in Cell and Developmental

Biology

Received: 14 December 2020

Accepted: 19 February 2021

Published: 07 April 2021

Citation:

Jing N, Gao W-Q and Fang $Y-X$ (2021) Regulation of Formation,

Stemness and Therapeutic

Resistance of Cancer Stem Cells. Front. Cell Dev. Biol. 9:641498. doi: 10.3389/fcell.2021.641498 orchestrate the characteristic of CSCs by the three elements and potential therapeutic strategies. We also summarize how several key regulatory factors function in the regulation of not only the formation and stemness maintenance, but also the therapeutic resistance of CSCs. Thus, future studies focusing on these key factors would be helpful for the development of novel drugs targeting CSCs.

Keywords: cancer stem cells, therapeutic resistance, tumor microenvironment, stemness, stemness maintaining

Abbreviations: ABCG2, ATP binding cassette subfamily G member2; ALDH, aldehyde dehydrogenase; ALDH1A3, aldehyde dehydrogenase 1A3; ALKBH5, alkB homolog 5; AR, androgen receptor; ASCL1, Achaete-Scute Complex-Like 1; ATG14, autophagy related 14; BCSCs, breast cancer stem cells; CCL2, chemokine ligand 2; CCSCs, colorectal cancer stem cells; CDKN1C, cyclin dependent kinase inhibitor 1C; CRC, colorectal cancer; CREBBP, Cyclic AMP response element binding protein; CSCs, cancer stem cells; DDK1, Dickkof-1; DNMT, DNA methyltransferase; E2F1, E2F transcription factor 1; EZH2, enhancer of zeste 2 polycomb repressive complex 2 subunit; FANCD2, FA complementation group D2; FGF4, fibroblast growth factor 4; FOXM1, forkhead box M1; FOXP1, forkhead box P1; GATA3, GATA binding protein 3; GBM, Glioblastoma; GCa, gastric cancer; GCSCs, gastric cancer stem cells; GLI1, GLI family zinc finger 1; GLI2, GLI family zinc finger 2; GPR371L, G protein-coupled receptor 37-like 1; GSCs, glioblastoma stem cells; H3K27me3, histone H3 lysine 27 tri-methylation; HAND2, heart and neural crest derivatives expresses 2; HCC, hepatocellular carcinoma; HGF, hepatocyte growth factor; HMGA2, high mobility group AT-hook 2; hnRNPK, heterogeneous nuclear ribonucleoprotein K; HNSCC, head and neck squamous cell carcinoma; HOXC8, homeobox C8; IFN- $\gamma$, interferon- $\gamma$; IGF-II, insulin-like growth factor II; IL-33, interleukin 33; IL-6, interleukin 6; JAK2, janus kinase 2; JMJD1C, jumonji domain containing 1C; KDM3A, lysine demethylase 3A; KDM3B, lysine demethylase 3B; KLF4, Kruppel like factor 4; LCSCs, liver cancer stem cells; LPECs, liver parenchymal endothelial cells; LT-HSCs, long-term hematopoietic stem cells; MaSCs, mammary stem cells; M-CSF, macrophage colony stimulating factor; MEG3, maternally expressed 3; MORC2, MORC family CW-type zinc finger 2; mTOR, mechanistic target of rapamycin kinase; MYT1, myelin transcription factor 1; NANOG, nanog homeobox; NANOGP8, Nanog homeobox retrogene P8; NF-kB, nuclear factor kappa B; NKX6-2, NK6 homeobox 2; NSCLC, non-small cell lung cancer; OCSCs, ovarian cancer stem cells; OCT4, octamer-binding transcription factor 4; OCT6, octamer-binding transcription factor 6; PAK1, p21 (RAC1) activated kinase 1; Par3, pulmonary adenoma resistance 3; PCNA, proliferating cell nuclear antigen; PCSCs, prostate cancer stem-like cells; PHF20, plant homeodomain finger-containing protein 20; PHOX2B, paired like homebox 2B; Prlr, prolactin receptor; PRMT5, protein arginine methyltransferase 5; PTK7, protein tyrosine kinase 7; SHMT1, serine hydroxymethyltransferase 1; SKP2, S-phase kinase associated protein2; SOCS3, suppressor of cytokine signaling 3; SOX2, SRY-box transcription factor 2; STAT3, signal transducer and activator of transcription 3; STAT5, signal transducer and activator of transcription 5; SUV39H1, histone H3 lysine 9 methyltransferase; TCF7, transcription factor 7; TRIB3, tribbles pseudokinase 3; WISP1, WNT1 inducible signaling pathway protein 1; Zeb1, zinc finger E-box binding homeobox 1 . 


\section{INTRODUCTION}

Cancer stem cells hypothesis endorses that CSCs are a subset of cancer cell subpopulations in the tumor, which are considered to be responsible for tumor initiation, recurrence, metastasis, and therapeutic resistance (Visvader and Lindeman, 2012). Because of the key contribution of CSCs to tumor heterogeneity and consequential resistance to therapy (Kesh et al., 2020), it is urgent to explore underlying mechanisms. While mutations of driver genes are key to the initiation of CSCs, epigenetic factors such as DNA methylation (Toh et al., 2017) and non-coding RNAs deregulation (Wang Y. et al., 2015) on multiple stem cell signal pathways including the Wnt signaling (HOXA5 Counteracts Stem Cell Traits by Inhibiting Wnt Signaling in Colorectal Cancer), Notch signaling (Xiao et al., 2017), and Hedgehog signaling (Zhu and Wang, 2020) are of equal importance. In addition, a cell-to-cell communication between CSCs and other types of adjacent cells such as endothelial cells (Krishnamurthy et al., 2010), macrophages (Fang et al., 2017), and fibroblasts (Fiori et al., 2019) in the tumor microenvironment also play influential roles. In this review, we summarize genetic and epigenetic regulatory factors and tumor microenvironment inducers on the regulation of the formation, stemness maintenance and therapeutic resistance of CSCs, and propose potential strategies for cancer therapy targeting CSCs.

\section{REGULATION OF FORMATION OF CSC}

Over the past two decades, regulation of CSCs formation by genetic, epigenetic and tumor microenvironmental elements has been highlighted (Figure 1). First, chromatin remodeling for gene rearrangement (Liau et al., 2017) and accumulation of gene mutations (Davies et al., 2011) by key compounds are major genetic transformations in somatic stem cells from normal tissues or bone marrow to regain phenotypes and profiling characteristics of CSCs. Second, epigenetic modification through methylation and non-coding RNAs can give rise to deregulation and gain-of-function in somatic stem cells to form a CSCs-like state. Third, soluble cytokines/chemokines secreted by adjacent cells (e.g., fibroblasts, endothelial cells, and immunocytes) in tumor microenvironment can also induce the initiation of CSCs (Table 1).

\section{Chromatin Remodeling}

A key study has given evidences that in glioblastoma stem cells (GSCs) elevated expression of Achaete-Scute ComplexLike 1 (ASCL1) can promote the proliferation of quiescent cells and their differentiation into neurons by binding the chromatin at enhancer region of the neural target genes to activate the transcription of these target genes, including NK6 homeobox 2 (NKX6-2), high mobility group AT-hook 2 (HMGA2), G protein-coupled receptor 37-like 1 (GPR37l1) and myelin transcription factor 1 (MYT1). Among them, MYT1 can directly inhibit NOTCH signal during neural development of mice, indicating a coordinated role of ASCL1 in cell fate determination program (Park et al., 2017). Another study has reported that the MORC family CW-type zinc finger 2(MORC2) protein is a new chromosome remodeling protein that changes the structure of chromosomes in an ATPase-dependent manner to effectively repair DNA damage induced by ion irradiation (Li et al., 2012). Importantly, p21 (RAC1) activated kinase 1 (PAK1) protein kinase-mediated phosphorylation of MORC2 inhibits expression of tumor suppressor gene $p 21$ and cytoskeleton-related gene Argbp2 to promote gastric tumorigenesis (Wang G. L. et al., 2015).

\section{Gene Mutation}

As a key tumor-suppressive transcriptional factor, although the inactivation of P53 alone is not sufficient to drive hepatocellular carcinoma (HCC) tumorigenesis, evidences has been provided that inactivation of P53 along with overexpression of oncogenes such as c-Myc makes hepatocytes more prone to oncogenic transformation and to acquire CSCs characteristics so to increase stem genes expression (Liu et al., 2017). Another oncogenic driver gene homeobox C8 (Hoxc8) has also been reported as an important regulator of the formation of stem cells and can act as a regulator of breast cancer cells differentiation. Hoxc8 silencing endows mammary gland cells with stem cells potential and an increased CSCs population (Shah et al., 2017). On the other hand, cyclic AMP response element binding protein (CREBBP) was recently shown to be a novel inhibitor for the initiation of CSCs. It has been found that mice with early deletion of CREBBP in the hematopoietic stem and progenitor cells compartment shows changes in DNA damage response and increased frequency of invasive lymphoproliferative disorders/lymphoma. Loss of CREBBP leads to the subsequent development of mature lymphoid malignancies and the generation of cancer progenitor cells (Horton et al., 2017). Our previous work demonstrated that loss of pulmonary adenoma resistance 3 (Par3), a key cell polarity molecule, is tightly involved in the promotion of prostatic tumorigenesis, which is related to the change of cell division modes in cancer progenitor cells (Zhou et al., 2019). In addition to loss-of-function gene mutation, our recent studies also indicate that elevated expression of zinc finger E-box binding homeobox 1 (ZEB1), an important epithelial-to-mesenchymal transition related transcription factor, in prostate basal stem cells which is associated with the formation of CSCs in the prostate promotes androgen independence of prostate cancer (Wang X. et al., 2020). Similarly, upregulation of NF-kB was found to enhance the activity of the Wnt pathway and in turn to induce the dedifferentiation of non-stem cells and acquisition of cancer stem cells-like properties (Schwitalla et al., 2013). In addition, a recent study reported two missense mutations of CHD4 gene $\left(\mathrm{CHD} 4^{\mathrm{R} 975 \mathrm{H}}\right.$ and $\left.\mathrm{CHD} 4^{\mathrm{R} 1162 \mathrm{~W}}\right)$ that were located in the ATPase binding domain of CHD4. It was found that both mutations can reduce the half-life of $\mathrm{CHD} 4$ protein and inactivate CHD4 protein to promote the phenotype of CSCs through the TGF$\beta / C D 133$ pathway, expand the CSCs population, and enhance the progression of endometrial cancer (Li et al., 2018).

\section{Upregulation of Stemness Related Factors}

A recent study showed that JAK2 can interact with PAK1 to regulate the nuclear translocation of PAK1 and Stat3. The 


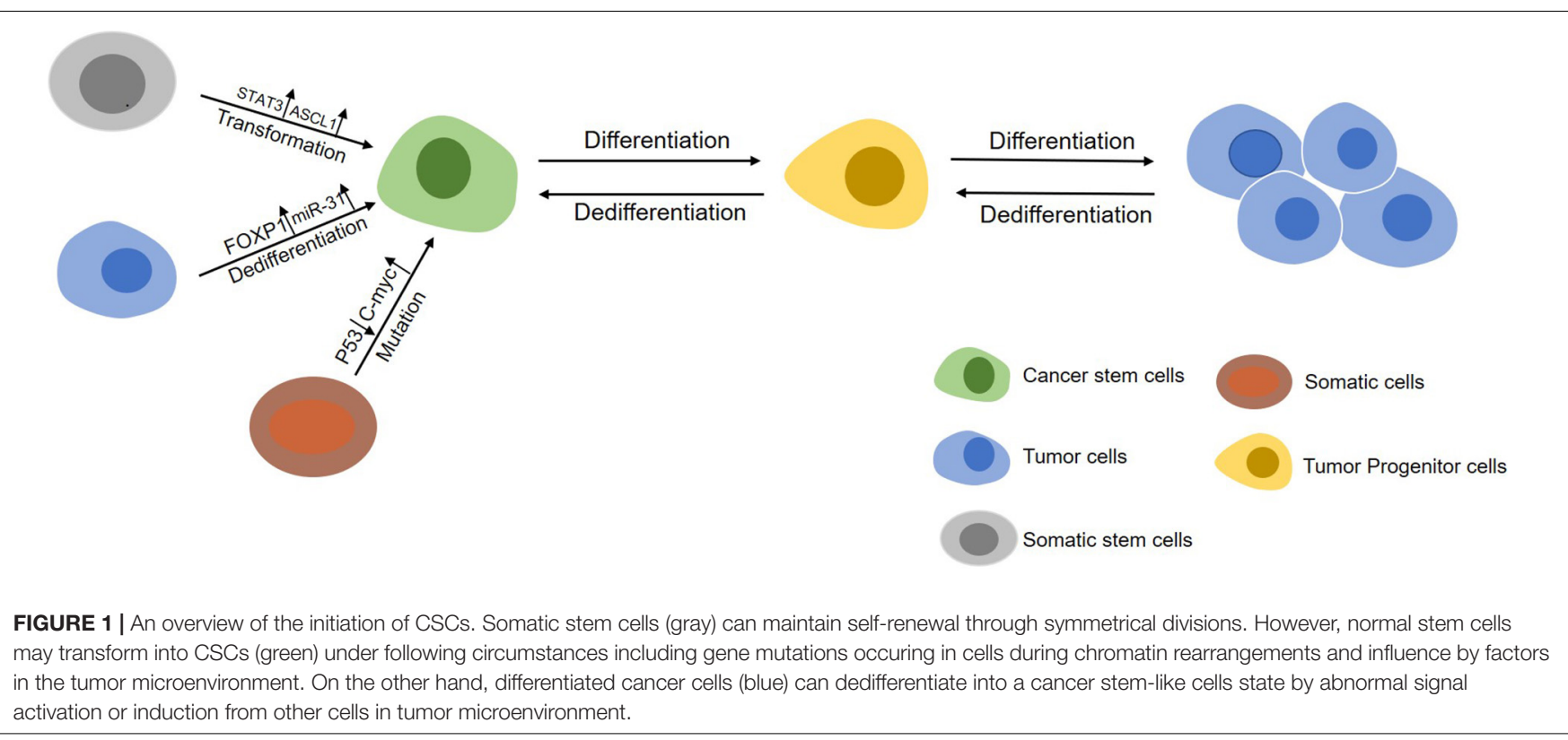

Stat3/PAK1 complex is recruited to the IL-6 promoter and induces the transcription of IL- 6 gene, a stemness related factor for the formation of BCSCs through JAK2/PAK1/Stat3/IL6 signaling (Kim et al., 2019). Additionally, a recent study demonstrated that FOXP1 can function as an oncogene and a CSCs driver gene in epithelial ovarian cancer cells. FOXP1 upregulates the transcriptional activities of four key stemness factors, ATP Binding Cassette Subfamily G Member2 (ABCG2), octamer-binding transcription factor 4 (OCT4), nanog homeobox (NANOG) and SOX2, to promote CSCs-like features in ovarian cancer cells (Choi et al., 2016).

\section{Histone and mRNA Methylation}

It has been well reported that the change of post-translational modification profiling, especially the methylation of histones is tightly associated with tumorigenesis. Recently, loss of histone methylation in specific gene promoters has been indicated to be associated with the formation of CSCs and. For example, the histone demethylases of the lysine demethylase 3 (KDM3) family, including KDM3A, KDM3B and JMJD1C, can remove methyl groups from $\mathrm{H} 3 \mathrm{~K} 9 \mathrm{me} 2$ and simultaneously recruit histone methyltransferase MLL1 to promote H3K4 methylation and then enhance the transcription of Wnt target genes. KDM3 family has also been found to play a key role in the carcinogenic potential of CSCs by regulating $\mathrm{Wnt} / \beta$-catenin-mediated transcription. In contrast, depletion of KDM3 significantly inhibits the germinal potential and survival of CSCs (Li et al., 2017). In addition, studies have shown that co-exposure of arsenic and benzo-a-pyrene has a synergistic effect on the induction of malignant transformation of CSCs in tumorigenesis by increasing expression of histone H3 lysine 9 methyltransferase (SUV39H1). Upregulation of SUV39H1 increases H3K9 dimethylation (H3K9me2) to decrease expression of tumor-suppressive suppressor of cytokine signaling 3 (SOCS3), which leads to a significantly enhanced activation of
Akt and Erk1/2 for transformation of CSCs and tumorigenesis (Wang Z. S. et al., 2020). On the other hand, N6 methyltransferase and demethylase can regulate gene expression and cell fate through dynamic and reversible N6 methyladenosine (m6A) RNA modification. Evidences have been found that the m6A demethylase alkB homolog 5 (ALKBH5) is highly expressed in CSCs. Silencing ALKBH5 can inhibit the proliferation of CSCs. ALKBH5 enhances its expression by demethylating the nascent transcripts of forkhead box M1 (FOXM1) and the relevant non-coding RNA, FOXM1-AS. FOXM1-AS can promote the combination of ALKBH5 and FOXM1 nascent transcripts. Deleting ALKBH5 and FOXM1-AS blocks the tumorigenicity of CSCs (Zhang S. C. et al., 2017).

\section{MicroRNA}

Accumulating researches indicated that dysregulation microRNA is an early event involved in the initiation of CSCs and tumorigenicity (Nasr et al., 2019; Yan D. J. et al., 2019; Yan X. L. et al., 2019). Recently, miR-31 has been found to be highly expressed in mammary stem cells (MaSCs) and breast cancer. It promotes mammary epithelial cell proliferation and MaSCs expansion in vivo by regulating various signaling pathways such as TGF- $\beta$ and Prlr/Stat5. While defected miR31 affects the growth of breast cancer, reduction of CSC numbers and metastasis of the tumors to the lung ( $\mathrm{Lv}$ et al., 2017), miR-200c has been indicated to be involved in the self-renewal process of stem cells by regulating expression of BMI and Suz12 genes. In addition, miR-200c has been identified as an important trigger for the transformation of MaSCs to breast cancer stem cells (BCSCs). Restoration of its expression can inhibit the clonality of BCSCs in vitro and the tumorigenicity in vivo (Shimono et al., 2009).

\section{LncRNA}

Similar to microRNA, lncRNA is also one of the key regulators of CSCs (Castro-Oropeza et al., 2018). In glioblastoma (GBM), 
TABLE 1 | Genes involved in the initiation of CSCs.

\begin{tabular}{|c|c|c|c|c|}
\hline Regulation model & Gene & Cancer type & Function & References \\
\hline \multirow[t]{2}{*}{ Chromatin remodeling } & Ascl1 & Glioblastoma & Cell proliferation & Park et al., 2017 \\
\hline & Morc2 & Gastric carcinoma & $\begin{array}{l}\text { Changing the structure of } \\
\text { chromosomes; DNA damage repair }\end{array}$ & Li et al., 2012; Wang Y. et al., 2015 \\
\hline \multirow[t]{8}{*}{ Gene mutation } & P53 & Hepatocellular carcinoma & Tumorigenesis & Liu et al., 2017 \\
\hline & $c-m y c$ & Hepatocellular carcinoma & Tumorigenesis & Liu et al., 2017 \\
\hline & Hoxc8 & breast cancer & Promoting cancer cell differentiation & Shah et al., 2017 \\
\hline & Crebbp & Lymphoma & Inhibiting the initiation of CSCs & Horton et al., 2017 \\
\hline & Par3 & Prostate cancer & Regulating cell division pattern & Zhou et al., 2019 \\
\hline & Zeb1 & Prostate cancer & Promoting EMT & Wang X. et al., 2020 \\
\hline & $N f-k B$ & Intestinal cancer & $\begin{array}{l}\text { Inducing the dedifferentiation of } \\
\text { non-stem cells }\end{array}$ & Schwitalla et al., 2013 \\
\hline & Stat3 & Breast cancer & Tumorigenesis & Kim et al., 2019 \\
\hline \multirow[t]{4}{*}{ Histone and mRNA methylation } & $K d m 3$ & Colorectal cancer & Promoting H3K4 methylation & Li et al., 2017 \\
\hline & Suv39h1 & Lung cancer & Increasing H3K9 dimethylation & Wang Z. S. et al., 2020 \\
\hline & Socs3 & Lung cancer & $\begin{array}{l}\text { Enhancing transformation of CSCs } \\
\text { and tumorigenesis }\end{array}$ & Wang Z. S. et al., 2020 \\
\hline & Alkbh5 & Glioblastoma & Promoting CSCs proliferation & Zhang S. C. et al., 2017 \\
\hline \multirow[t]{2}{*}{$\begin{array}{l}\text { Post-transcriptional regulation } \\
\text { by microRNA }\end{array}$} & $\operatorname{miR-31}$ & Breast cancer & $\begin{array}{l}\text { Promoting mammary epithelial cell } \\
\text { proliferation }\end{array}$ & Lv et al., 2017 \\
\hline & $\operatorname{miR}-200 c$ & Breast cancer & $\begin{array}{l}\text { Promoting transformation of MaSC } \\
\text { to breast cancer stem cells }\end{array}$ & Shimono et al., 2009 \\
\hline $\begin{array}{l}\text { Post-transcriptional regulation } \\
\text { by IncRNA }\end{array}$ & Meg3 & Glioblastoma & Inhibiting cell growth and migration & Buccarelli et al., 2020 \\
\hline \multirow[t]{3}{*}{ Induction by endothelial cells } & Nanogp8 & Colorectal cancer & Initiating CSCs & Wang et al., 2017 \\
\hline & Ptk7 & Head and neck squamous cell carcinoma & Promoting the phenotype of CSC & Yu et al., 2018 \\
\hline & $\operatorname{Ar}$ & Prostate cancer & $\begin{array}{l}\text { Promoting the transformation of } \\
\text { CSCs }\end{array}$ & Liao et al., 2017 \\
\hline
\end{tabular}

lncRNA MEG3 acts as a tumor suppressor and its low expression is significantly related to the short survival of GBM patients. Restoring expression of maternally expressed 3 (MEG3) inhibits cell growth and migration, thereby reducing the tumorigenic effect of GSCs and their invasive growth (Buccarelli et al., 2020).

\section{Endothelial Cells}

It has been reported that liver parenchymal endothelial cells can mediate the initiation of CSCs in colorectal cancer (CRC) in a paracrine manner by activating the Nanog homeobox retrogene P8 (NANOGP8) pathway (Wang et al., 2017). Additionally, conditioned medium from endothelial cells derived from tumor microvessels can restore the CSC phenotype of differentiated GBM, which is mediated by bFGF, a major soluble factor present in the conditioned medium (Fessler et al., 2015).

\section{Macrophages}

In tumor microenvironment, it has been found that IL33 induces macrophages to infiltrate into tumor tissues to produce prostaglandin E2 which makes tumor cells to acquire CSCs' stemness and to support proliferation of CSCs in CRC (Fang et al., 2017).

\section{Cancer-Associated Fibroblasts (CAFs)}

It has been shown that CAFs can increase the number of liver CSCs through a paracrine manner in which hepatocyte growth factor (HGF) activates c-Met/FRA1/HEY1 signaling to develop a fibrosis-dependent HCC (Lau et al., 2016). In head and neck squamous cell carcinoma (HNSCC), it was recently found that CAFs secretes periostin that significantly upregulates the CSCs-like phenotype, proliferation and invasion in HNSCC. Mechanically, periostin binds to protein tyrosine kinase 7 (PTK7) on the cell membrane of CSCs. This interaction activates downstream $\mathrm{Wnt} / \beta$-Catenin signaling to promote the phenotype of CSCs (Yu et al., 2018). In prostate cancer, androgen receptor can also be activated by prostate CAFs-secreted interferon- $\gamma$ (IFN- $\gamma$ ) and macrophage colony stimulating factor (M-CSF), which promotes the expression of stem cell markers in prostate cancer cells to acquire the characteristics of prostate cancer stemlike cells (PCSCs) (Liao et al., 2017).

\section{REGULATION OF STEMNESS OF CSC}

Cancer stem cells' stemness is responsible for tumor initiation capability, metastasis and therapeutic resistance. Thus, it is important to study the mechanism of regulating the stemness of CSCs for a better therapy of tumors (Figure 2). Enhancement of CSCs' stemness can be caused by activated stemness related signaling pathways, enhanced the capability of DNA damage repair or disordered epigenetic regulation of methylation and non-coding RNAs, and also can be induced by tumor microenvironment (Table 2). 


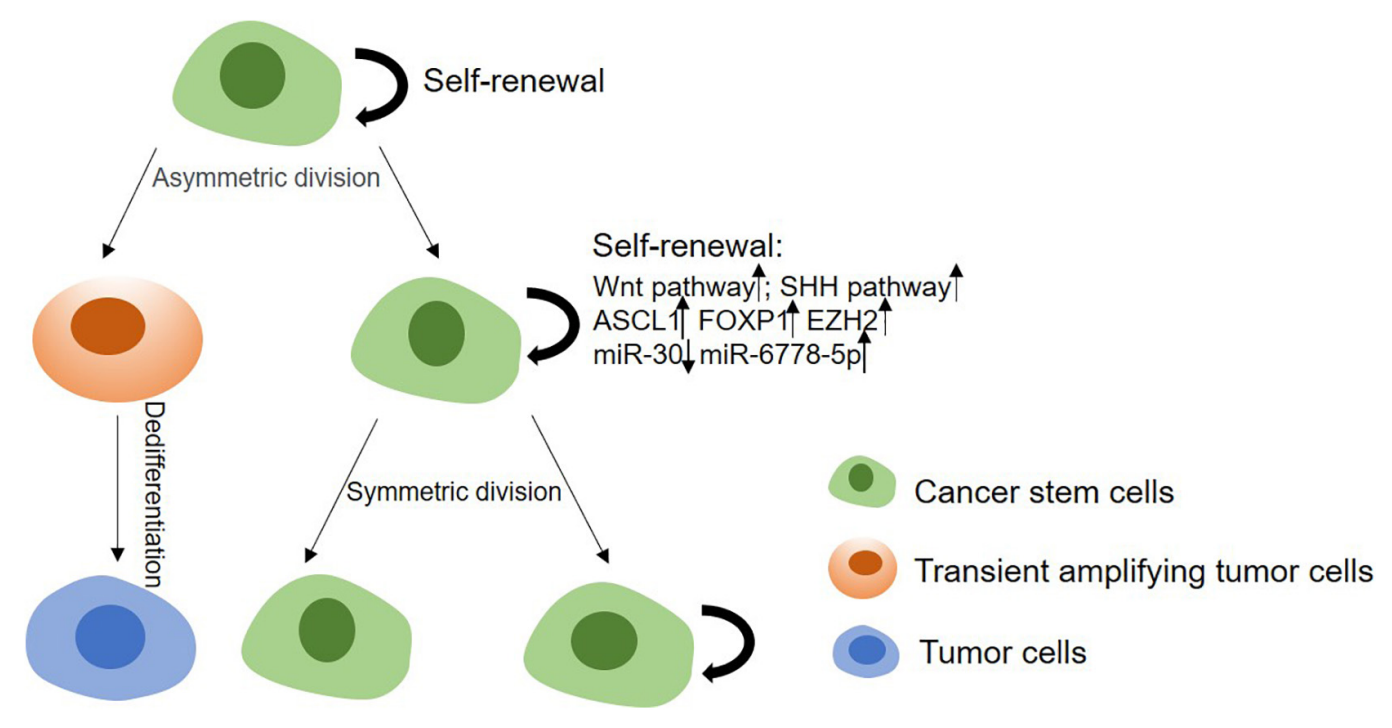

FIGURE 2 | The mechanism of stemness maintenance of CSCs. In CSCs model, CSCs can progress into solid tumors due to their self-renewal and proliferation capabilities. CSCs can give rise to transient amplifying cells, and then develop into committed pre-malignant progenitors, differentiated malignant cells. On the other hand, CSCs can renew and proliferate themselves through upregulating Wnt, Shh, Notch pathways, or enhancing DNA damage repair ability, etc.

\section{Changes in Stem Cell Signaling Pathways}

It is worth mentioning that the Wnt pathway is closely involved in the regulation of stemness in both somatic stem cells and CSCs (Matsui, 2016). A recent study demonstrated that tribbles pseudo-kinase 3 (TRIB3) induces and maintains stemness of colorectal cancer stem cells (CCSCs) by changing the homeostasis of CSCs' self-renewal and differentiation, which is mediated by forming a positive feedback loop between TRIB3 and Wnt/ $\beta$ catenin. Upregulation of TRIB3 expression enhances CCSCs properties, including prokaryotic size, continuous passage ability, and tumor initiation frequency (Hua et al., 2019). Consistent with this finding, our recent study also indicates that $\mathrm{WNT} / \beta$-Catenin signaling can preferentially direct symmetric cell division, one of the major regulatory signaling for a hierarchy of prostate epithelial cells (Wang et al., 2014), in hTERT ${ }^{\text {high }}$ PCSCs to improve the self-renewal (Zhang K. et al., 2017). In addition, a more recent study shows that plant homeodomain fingercontaining protein 20 (PHF20) is a crucial epigenetic regulator for sustaining the stem cell-like phenotype in GBM via regulation of the degradation of $\beta$-catenin in a WNT1 inducible signaling pathway protein 1 (WISP1)/biglycan (BGN) pathway dependent manner (Ma et al., 2020). Also ASCL1 was reported to promote Wnt signaling to induce Wnt target gene AXIN2 by inhibition of Dickkof-1 (DDK1) for the maintenance of GSCs (Rheinbay et al., 2013). Besides Wnt, the SHH pathway is also a key player in the stemness maintenance of CSCs (Samadani and Akhavan-Niaki, 2015). For example, it is reported that treatment of pancreatic cancer stem cells with GANT61, an inhibitor of GLI1 and GLI2, two SHH signaling downstream effectors can effectively reduce the characteristics of cancer stem cells. Furthermore, a simultaneous therapy of mechanistic target of rapamycin kinase (mTOR) inhibitor with GANT61 was confirmed as a more effective treatment for pancreatic cancer by inhibition of the stemness of pancreatic cancer stem cells (Miyazaki et al., 2016).

\section{DNA Damage Repair}

Recently a DNA damage repair related ubiquitin-binding enzyme RAD6 is found to regulate mutagenic DNA damage tolerance to respond to various genomic damages, including chemotherapy and radiation therapy in ovarian cancer. Elevated RAD6 expression promotes the development of stem celllike phenotypes and resistance to carboplatin by stimulating the monoubiquitination of FA complementation group D2 (FANCD2) and proliferating cell nuclear antigen (PCNA), both of which are important for drug-induced DNA crosslink repair and DNA damage tolerance mechanisms, respectively (Somasagara et al., 2017).

\section{DNA and Histone Methylation}

DNA methylation is also an important epigenetic regulatory mode to regulate the stemness of CSCs. For example, it is revealed that DNA methyltransferase improves the stemness of colorectal CSCs and that reversely its inhibitor 5-Aza- $2^{\prime}$-deoxycytidine (5-AzaDC) reduces the abundance of colorectal CSCs by downregulation of DNA hypermethylation of the canonical Wnt pathway (Li et al., 2018). Similar to DNA methylation, histone methylation modifying enzymes can promote gene expression to improve the stemness of CSCs (Norollahi et al., 2019). It has been reported that protein arginine methyltransferase 5 (PRMT5), an arginine methyltransferase, can be recruited to the promoter of forkhead box P1 (FOXP1) to facilitate H3R2me2s, SET1 recruitment, $\mathrm{H} 3 \mathrm{~K} 4 \mathrm{me} 3$, and FOXP1 expression in BCSCs so that the number of BCSCs is increased (Chiang et al., 2017). Another famous histone lysine methyltransferase is enhancer of zeste 2 polycomb repressive complex 2 (Ezh2), which is responsible 
TABLE 2 | Genes involved in the stemness maintenance of CSCs.

\begin{tabular}{|c|c|c|c|c|}
\hline Regulation model & Gene & Cancer type & Function & References \\
\hline \multirow[t]{3}{*}{ Gene mutation } & Trib3 & Colorectal cancer & $\begin{array}{l}\text { Changing the homeostasis of } \\
\text { CSCs' self-renewal and } \\
\text { differentiation }\end{array}$ & Hua et al., 2019 \\
\hline & Phf20 & Glioblastoma & $\begin{array}{l}\text { Sustaining the stem cell-like } \\
\text { phenotypes }\end{array}$ & Ma et al., 2020 \\
\hline & Shh & Pancreatic cancer & $\begin{array}{l}\text { Sustaining the characteristics of } \\
\text { CSCs }\end{array}$ & Miyazaki et al., 2016 \\
\hline DNA damage repair & Rad6 & Ovarian cancer & $\begin{array}{l}\text { Regulating mutagenic DNA } \\
\text { damage tolerance }\end{array}$ & Somasagara et al., 2017 \\
\hline \multirow[t]{4}{*}{ DNA and histone methylation } & Prmt5 & Breast cancer & Enhancing the stemness of CSCs & Chiang et al., 2017 \\
\hline & Foxp 1 & Breast cancer & Enhancing the stemness of CSCs & Chiang et al., 2017 \\
\hline & Set1 & Breast cancer & Enhancing the stemness of CSCs & Chiang et al., 2017 \\
\hline & Ezh2 & Glioblastoma Breast cancer & $\begin{array}{l}\text { Promoting the self-renewal and } \\
\text { tumorigenetic ability of CSCs }\end{array}$ & $\begin{array}{l}\text { Suva et al., 2009; van Vlerken et al., } \\
2013\end{array}$ \\
\hline \multirow{3}{*}{$\begin{array}{l}\text { Post-transcriptional regulation } \\
\text { by microRNA }\end{array}$} & $\operatorname{miR}-30$ & Breast cancer & Inhibiting the self-renewal of CSCs & Yu et al., 2010 \\
\hline & $\operatorname{miR}-7$ & Prostate cancer & $\begin{array}{l}\text { Promoting tumor growth and } \\
\text { metastasis }\end{array}$ & Chang et al., 2015 \\
\hline & $\operatorname{miR}-6778-5 p$ & Gastric cancer & $\begin{array}{l}\text { Mediating the compensatory } \\
\text { activation of cytoplasmic carbon } \\
\text { metabolism }\end{array}$ & Zhao et al., 2020 \\
\hline \multirow[t]{3}{*}{$\begin{array}{l}\text { Formation RNA-protein } \\
\text { complex by IncRNA }\end{array}$} & Lnc TCF7 & Liver cancer & $\begin{array}{l}\text { Promoting the self-renewal of CSCs } \\
\text { and tumor proliferation }\end{array}$ & Wang Y. et al., 2015 \\
\hline & Lnc $\beta-C a t m$ & Liver cancer & $\begin{array}{l}\text { Promoting the interaction between } \\
\mathrm{EZ} \mathrm{H} 2 \text { and } \beta \text {-catenin }\end{array}$ & Zhu et al., 2016 \\
\hline & Lnc LBCS & Bladder cancer & $\begin{array}{l}\text { Inhibiting the tumor initiation and } \\
\text { CSCs self-renewal ability }\end{array}$ & Chen et al., 2019 \\
\hline Induction by endothelial cells & $B m i-1$ & Head and neck squamous cell carcinoma & $\begin{array}{l}\text { Promoting the stemness } \\
\text { maintenance of CSCs }\end{array}$ & Krishnamurthy et al., 2010 \\
\hline Induction by macrophages & Stat3 & Murine breast cancer & $\begin{array}{l}\text { Increasing the expression of the } \\
\text { stemness maintenance gene SOX2 }\end{array}$ & Yang et al., 2013 \\
\hline Induction by CAFs & Fgf4 & Ovarian cancer & $\begin{array}{l}\text { Maintaining self-renewal capability } \\
\text { of CSCs }\end{array}$ & Yasuda et al., 2014 \\
\hline
\end{tabular}

for catalyzing methylation of lysine 27 (H3K27) of histone H3 and is indispensable for the maintenance and proliferation of cancer stem cells (Wen et al., 2017). Studies on both GSCs and BCSCs have found that knock-down of Ezh2 or inhibition its methyltransferase activity can inhibit the self-renewal and tumorigenetic ability of GSCs (Suva et al., 2009; van Vlerken et al., 2013). Mechanistically, Ezh2 can inhibit the ability of DNA break repair by reducing expression of DNA break repair genes to promote the growth of CSCs (Stefansson and Esteller, 2011).

\section{MicroRNA}

Accumulating evidences reveal that microRNAs play key roles in regulation of not only CSCs' initiation but also the maintenance of CSCs' stemness (Fang et al., 2015). For instance, ectopic expression of miR-30 can inhibit the self-renewal ability of BCSCs in breast cancer xenografts to reduce tumor occurrence and metastasis (Yu et al., 2010). On the other hand, as Drosha is essential for the biosynthesis of microRNA, abnormal expression (Zhang et al., 2016) or function-loss of Drosha (Xu et al., 2017) are related to the malignancy of tumors. In our previous studies, we found that in prostate cancer impaired recruitment of Drosha to the precursor of miR-7 (pri-miR-7) reduces production of mature miR-7, which leads to overexpression of its target gene Kruppel like factor 4 (KLF4), one of the key stemness gene, to enhance the stemness of PCSCs for promotion of tumor growth and metastasis (Chang et al., 2015). However, a recent study has reported an unconventional microRNA, miR-6778-5p, which functions in a Drosha independent matter and acts as an important regulator for maintaining CSCs stemness in Drosha-silenced or low expressed gastric cancer (GCa). It has been found that in Drosha silenced GCa cells, miR-6778-5p positively regulates expression of its host gene serine hydroxymethyltransferase 1 (SHMT1), a key regulator in the folate-dependent serine/glycine interconversion, to mediate the compensatory activation of cytoplasmic carbon metabolism and in turn plays an important role in maintenance of the stemness of gastric cancer stem cells (GCSCs) (Zhao et al., 2020).

\section{LncRNA}

Over past decades, increased studies have revealed that lncRNAs act as one of the key regulators to maintain the stemness of CSCs via formation of multiple functional RNA-protein complex (Castro-Oropeza et al., 2018). In HCC, LncTCF7 is upregulated 


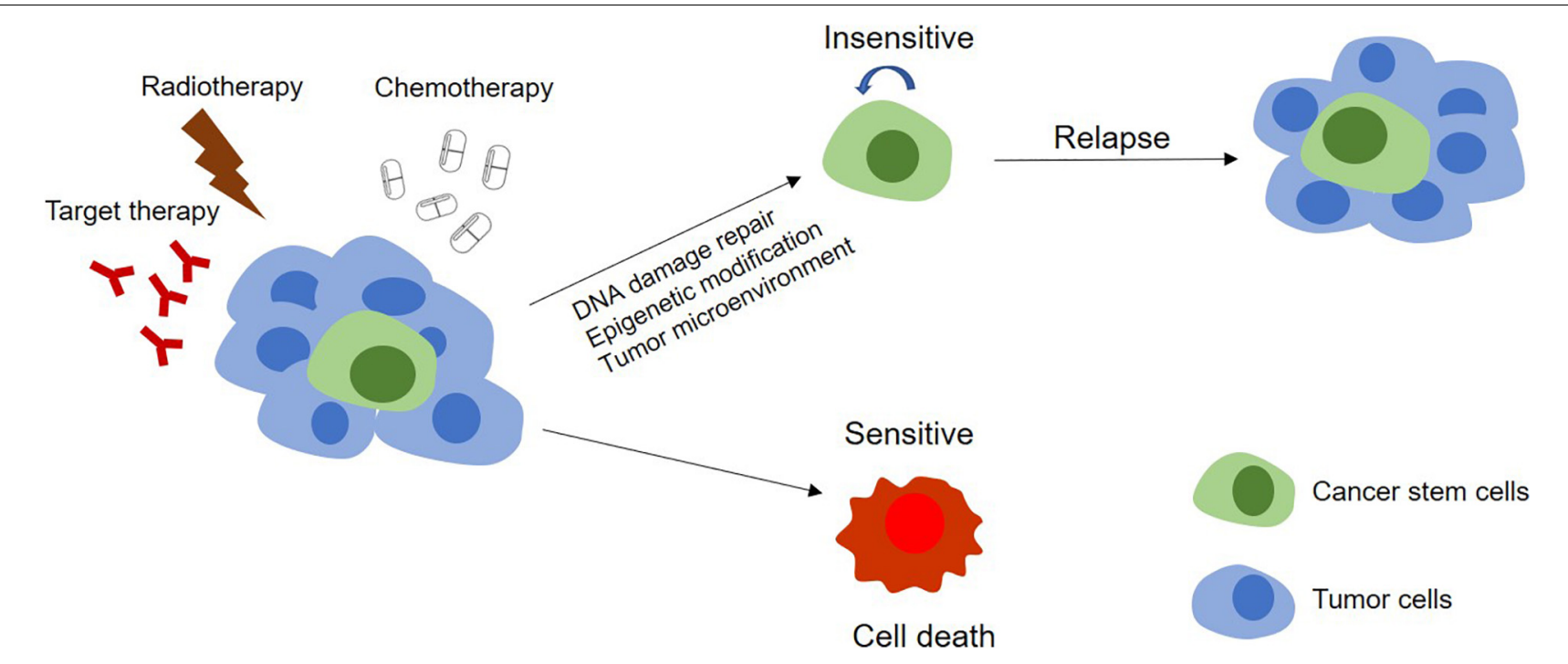

FIGURE 3 | Models of tumor therapeutic resistance. In CSCs model, therapy resistance can be mediated by stem cells. In this model, the tumor contains a small population of CSCs and their differentiated offsprings. With chemotherapy, radiotherapy, or targeted therapy, the DNA damage repair, epigenetic modification, and the effect of the tumor microenvironment on these CSCs make themselves become insensitive to treatments and survive the therapy. The completely differentiated tumor cells are sensitive to treatments and will be killed. Surviving CSCs can further proliferate and differentiate, leading to tumor relapse.

TABLE 3 | Genes involved in the therapy resistance of CSCs.

\begin{tabular}{|c|c|c|c|c|}
\hline Regulation model & Gene & Cancer type & Function & References \\
\hline \multirow[t]{5}{*}{ Gene mutation } & Cd133 & Lung cancer Glioblastoma Prostate cancer & Regulating CSCs through Notch pathway & Liu et al., 2013 \\
\hline & Aldh1 & Non-small cell Lung cancer & Driving CSCs into a dormant state & Dai et al., 2016 \\
\hline & Pi3k & Cervical cancer & Driving CSCs out of a dormant state & Jo et al., 2008 \\
\hline & Cd10 & Head and neck cancer & Inducing overexpression of OCT3/4 & Fukusumi et al., 2014 \\
\hline & Cd271 & Esophageal squamous cell carcinoma & $\begin{array}{l}\text { Resistanting to DDP and 5-FU treatment in } \\
\text { CSCs }\end{array}$ & Li et al., 2015 \\
\hline Regulation by microRNA & $\operatorname{miR}-450 B-5 P$ & Colorectal cancer & Inhibiting the resistance to chemotherapy & Jin et al., 2016 \\
\hline \multirow[t]{3}{*}{$\begin{array}{l}\text { Gene transcription changed by } \\
\text { IncRNA }\end{array}$} & NRAD1 & Triple-negative breast cancer & $\begin{array}{l}\text { Promoting tumor growth and resistance to } \\
\text { chemotherapy }\end{array}$ & Vidovic et al., 2020 \\
\hline & $H 19$ & Colorectal cancer & $\begin{array}{l}\text { Activating } \beta \text {-catenin and inducing inhibition the } \\
\text { stemness of CSCs }\end{array}$ & Ren et al., 2018 \\
\hline & Stat3 & Liver cancer & $\begin{array}{l}\text { Enhancing the expression of stemness } \\
\text { associated genes and the potential of } \\
\text { chemotherapy resistance }\end{array}$ & Wan et al., 2014 \\
\hline Induction by CAFs & $\mathrm{Cd} 44$ & Several cancers & Relating to the antioxidant effect of CSCs & Kinugasa et al., 2014 \\
\hline
\end{tabular}

in liver cancer stem cells (LCSCs) for regulation of LCSCs self-renewal and tumor proliferation. Mechanistically, LncTCF7 recruits the SWI/SNF complex to anchor on the promoter of its host gene TCF7 and improves the tumorigenic activity of LCSCs by activation of TCF7 transcription and Wnt signaling (Wang Y. et al., 2015). Studies have also shown that $\operatorname{lnc} \beta$-Catm can promote the interaction between EZH2 and $\beta$-catenin and enhance the methylation of $\beta$-catenin by EZH2. Methylation of $\beta$-catenin inhibits its phosphorylation and ubiquitination, and eventually activates $\mathrm{Wnt} / \beta$-catenin pathway to enhance the stemness of LCSCs (Zhu et al., 2016). Unlike oncogenic lncRNAs, tumor suppressive lncRNAs are usually repressed to attenuate their inhibitory effect on the stemness of CSCs. For example, Lnc-LBCS is observed to be significantly downregulated in bladder cancer stem cells, which inhibits the tumor initiation and CSCs self-renewal ability in vivo and in vitro. Lnc-LBCS directly binds to hnRNPK and EZH2 to form a complex, by which mediates H3K27me3 to inhibit the transcription of SOX2, an essential transcriptional factor for the self-renewal of CSCs (Chen et al., 2019).

\section{Endothelial Cells}

Increasing evidences show that the factors secreted by endothelial cells play an important role in the self-renewal and survival of CSCs (Krishnamurthy et al., 2010). It is reported that Bmi-1 secreted by endothelial cells can promote the stemness maintenance of $\mathrm{ALDH}^{+} \mathrm{CD} 44^{+}$stem-like cells in HNSCC (Krishnamurthy et al., 2010). Also endothelial cells was found to secrete vascular secretion factors and activate the 
NOTCH pathway in long-term hematopoietic stem cells (LTHSCs) through a direct cell-to-cell contact, thereby stimulating the growth of LT-HSCs and contributing to their stemness maintenance (Butler et al., 2010).

\section{Macrophages}

Previous studies have proven that macrophages can be recruited into tumor tissues and be transformed into tumorassociated macrophages (TAMs), thereby providing a favorable microenvironment for the occurrence and development of cancer (Hashimoto et al., 2016). These TAMs not only prevents $\mathrm{T}$ cells from attacking tumor cells, but also secretes a series of inflammatory factors to enhance the stemness of tumor cells (Chen et al., 2018). For example, for the purpose of enhancing the expansion and tumorigenic potential of CSCs, TAMs secrete IL-6 6 and EGF to activate the STAT3 signaling in CSCs to enhance expression of the stemness gene SOX2 (Yang et al., 2013).

\section{CAFs}

It has been reported that co-inoculation of fibroblasts with ovarian cancer stem cells (OCSCs) in nude mouse significantly increases the tumorigenesis ability in vivo caused by an elevated expression of fibroblast growth factor 4 (FGF4) to maintain selfrenewal capability in OCSCs (Yasuda et al., 2014). Similarly, CAFs can also promote expression of CSCs markers through TGF- $\beta$ signaling to maintain the stemness of scirrhous gastric cancer cells (Hasegawa et al., 2014). In addition, CAFs derived from lung cancer patients are found to have potential to maintain the stemness of LCSCs in a paracrine manner through the insulinlike growth factor II (IGF-II)/IGF1 receptor (IGF1R)/Nanog axis (Chen et al., 2014).

\section{REGULATION OF THERAPEUTIC RESISTANCE OF CSC}

A major challenge of cancer therapy is the resistance to chemotherapy, radiotherapy, and anti-tumor drugs, which is mainly caused by the existence of CSCs (Figure 3). CSCs can keep themselves at a dedifferentiated state so to resistant to the treatment by overexpression of therapeutic resistance related genes and improvement of the ability of DNA damage repair, by deregulation of related non-coding RNAs and by interaction with other types of adjacent cells in microenvironment as well (Table 3).

\section{Abnormal Expression of Therapeutic Resistance Related Genes}

Previous studies have shown that high expression of CD133 is not only one of the most common markers for CSCs, but also tightly related to their capability of self-renewal as well as drugresistance (O'Brien et al., 2007). Analysis of lung cancer xenograft tissue showed that cisplatin treatment increases the proportion of $\mathrm{CD} 133^{+}$cells caused by increasing the cleavage of Notch 1 to activate the Notch pathway. Treatment with $\gamma$-secretase inhibitor DAPT or Notch1 specific shRNA can significantly inhibit the

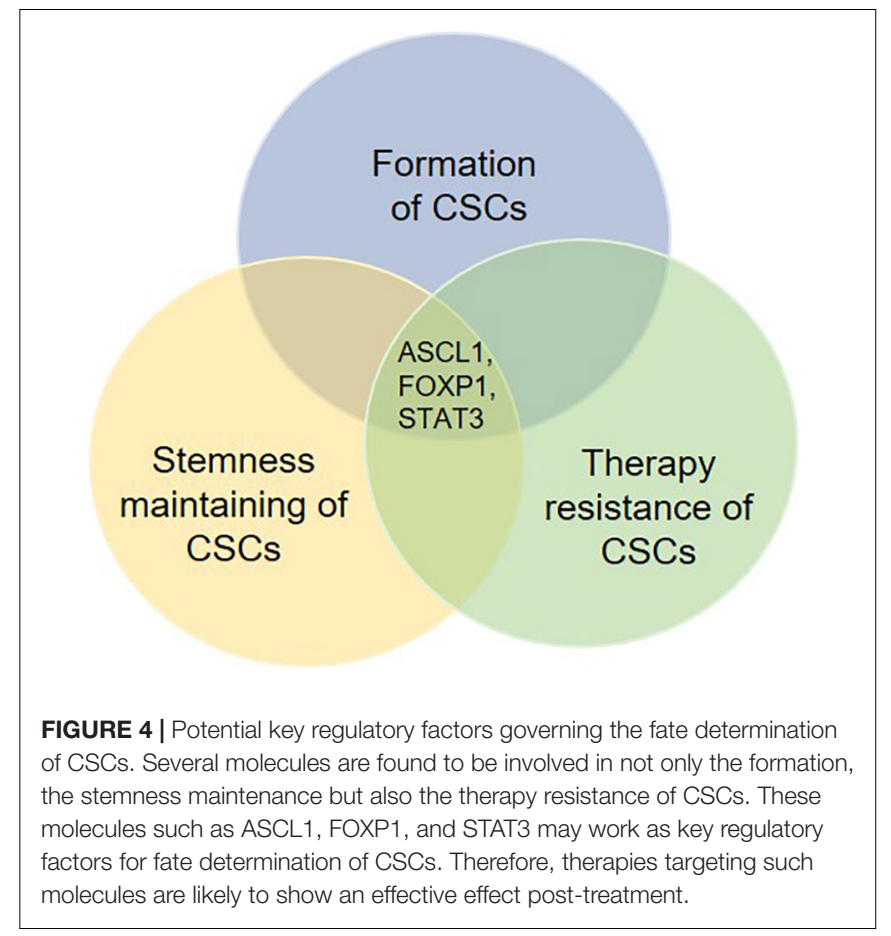

enrichment of cisplatin-induced $\mathrm{CD} 133^{+}$cells and enhance their sensitivity to doxorubicin and paclitaxel (Liu et al., 2013). Similar to this finding, our recent study also demonstrated that inhibition of the Notch pathway appears to be a promising adjuvant therapy of androgen deprivation therapy (ADT) for prostate cancer (Cui et al., 2018). In addition, it has also been shown that CD133+ glioblastoma is more effective in repairing DNA damage than $\mathrm{CD} 133^{-}$cells with more sensitive checkpoint activation (Bao et al., 2006). Based on the fact that a dormant state of CSCs plays a key role in resistance of anti-tumor drugs (Kleffel and Schatton, 2013). Dai et al. (2016) found that increased expression of stem cell marker genes such as CD133 and ALDH1 can drive CSCs into the dormant state against the cytotoxicity of 5-fluorouracil (5-FU) in non-small cell lung cancer. On the other hand, inhibition of PI3K-AKT signal also causes dormancy. Under the condition of nutritional deficiency, the cancer cell-derived factors can promote CSCs' dormancy by inhibition of PI3K to induce cell autophagy (Jo et al., 2008). Besides CD133, overexpression of another CSC marker CD10 was reported to enhance the characteristics of CSC in HNSCC cells and plays an important role in anti-chemotherapy and anti-radiotherapy by inducing overexpression of OCT3/4 (Fukusumi et al., 2014). In addition, elevated expression of CD271, a member of tumor necrosis factor receptor superfamily, in CSCs enables them to survive better by resisting to DDP and 5-FU treatment (Li et al., 2015).

\section{DNA Damage Repair}

It has been reported that expression of multiple reactive oxygen species (ROS) scavengers, such as superoxide reductase and glutathione reductase (Skvortsov et al., 2015; Skvortsova et al., 2015), is upregulated in CSCs to reduce ROS-induced DNA and cell damage (Wang et al., 2013), so that the ROS-mediated 
apoptosis is prevented and the efficacy of chemotherapy and radiotherapy is attenuated (Dawood et al., 2014).

\section{MicroRNA}

It has been well-known that enhanced stemness of CSCs by deregulation of microRNA is involved in the treatment resistance in multiple cancers (Mens and Ghanbari, 2018). For example, it has been reported that expression of miR-450B$5 \mathrm{P}$ is significantly downregulated in recurrent CRC tissues to increase expression of its direct target SOX2 to enhance the stemness of CSCs and the resistance to chemotherapy (Jin et al., 2016). In addition, a recent study has shown that miR-29c-3p downregulates ATG14 by inducing the expression of FOXP1 to inhibit autophagy and promote cisplatin resistance in ovarian cancer cells (Hu et al., 2020).

\section{LncRNA}

It has been found in triple-negative breast cancer that a non-coding RNA, NRAD1, which is regulated by aldehyde dehydrogenase 1A3 (ALDH1A3) and acts as its downstream effector, plays a role in enhancement of CSCs characteristics, promotion of tumor growth and resistance to chemotherapy via binding to the chromatin to change gene transcription (Vidovic et al., 2020).

\section{Macrophages}

Accumulating studies demonstrated that macrophages or TAMs can induce therapeutic resistance in tumor via an interaction with CSCs (Sainz et al., 2016). It has been reported that IL-6 secreted by TAMs induces cell proliferation of CD $44^{+}$liver CSCs in its microenvironment by activating STAT3 PAGE signaling to enhance the expression of stemness associated genes and the potential of chemotherapy resistance (Wan et al., 2014). Similarly, TAMs can directly induce the stem cell-like properties and chemoresistance of pancreatic duct adenocarcinoma by activating signal transducer and activator of transcription 3 (STAT3) signal. Inhibition of TAMs by M-CSF or chemokine ligand 2 (CCL2) receptor inhibitors can lead to a reduction of the number of CSCs and improve the efficacy of chemotherapy (Mitchem et al., 2013).

\section{CAFs}

It was reported that a $\mathrm{CD} 10^{+} \mathrm{GPR} 77^{+} \mathrm{CAFs}$ subgroup can support tumor cells to promote resistance to chemotherapy by providing CSCs a suitable nest for growth (Su et al., 2018). In addition, it has been found that a large number of $\mathrm{CD} 44^{+}$ CAFs are usually located in the hypoxic part of the tumor

\section{REFERENCES}

Bao, S., Wu, Q., McLendon, R. E., Hao, Y., Shi, Q., Hjelmeland, A. B., et al. (2006). Glioma stem cells promote radioresistance by preferential activation of the DNA damage response. Nature 444, 756-760. doi: 10.1038/nature05236

Buccarelli, M., Lulli, V., Giuliani, A., Signore, M., Martini, M., D’Alessandris, Q. G., et al. (2020). Deregulated expression of the imprinted DLK1-DIO3 region in glioblastoma stemlike cells: tumor suppressor role of lncRNA MEG3. Neuro Oncol. 22, 1771-1784. doi: 10.1093/neuonc/noaa127 tissue. Data revealed that these $\mathrm{CD} 44^{+}$CAFs can produce and secrete several soluble factors which are related to the antioxidant effect of CSCs after they are absorbed by CSCs (Kinugasa et al., 2014). Besides a direct secretion of soluble factors, CAFs can also transfer molecules into CSCs mediated by exosomes, which induces therapeutic resistance of CSCs. For example, it has been reported that CAF delivers LncRNA H19-containing exosomes into CSCs. LncRNA H19 can activate $\beta$-catenin and act as an endogenous competitive RNA of miR-141 in CRC against the miR-141 induced inhibition on the stemness of CSCs.

\section{CONCLUSION}

Mounting evidence indicate that the formation and stemness maintenance of CSCs is a complicated process, which is caused by a synergistic regulation of multiple intracellular genetic and epigenetic effectors in cancer in combination with inducers from tumor microenvironment. In addition, these related regulatory mechanisms are directly or indirectly involved in the development of therapeutic resistance. Moreover, several key regulatory factors can regulate not only the formation and selfrenewal, but also the therapy resistance of CSCs (Figure 4). Therefore, it would be important for future studies to focus on these key factors. Targeting these key factors may be a good therapeutic strategy for the management of cancer by suppressing formation and self-renewal of CSCs' and facilitating the differentiation and elimination of CSCs.

\section{AUTHOR CONTRIBUTIONS}

NJ searched for original articles and wrote the manuscript. NJ, Y-XF, and W-QG provided the idea and designed the review. All authors reviewed the manuscript and approved the final manuscript.

\section{FUNDING}

This work was supported by the Chinese Ministry of Science and Technology Grant (2017YFA0102900 to W-QG), National Natural Science Foundation of China Grants (81874097 and 82072843 to Y-XF and 81630073 and 81872406 to W-QG), Science and Technology Commission of Shanghai Municipality Grant (20JC1417600 to W-QG), and KC Wong Foundation to W-QG.

Butler, J. M., Nolan, D. J., Vertes, E. L., Varnum-Finney, B., Kobayashi, H., Hooper, A. T., et al. (2010). Endothelial cells are essential for the self-renewal and repopulation of Notch-dependent hematopoietic stem cells. Cell Stem Cell 6, 251-264. doi: 10.1016/j.stem.2010.02.001

Castro-Oropeza, R., Melendez-Zajgla, J., Maldonado, V., and Vazquez-Santillan, K. (2018). The emerging role of lncRNAs in the regulation of cancer stem cells. Cell Oncol. 41, 585-603. doi: 10.1007/s13402-018-0406-4

Chang, Y. L., Zhou, P. J., Wei, L. Z., Li, W., Ji, Z. Z., Fang, Y. X., et al. (2015). MicroRNA-7 inhibits the stemness of prostate cancer stem-like cells 
and tumorigenesis by repressing KLF4/PI3K/Akt/p21 pathway. Oncotarget 6, 24017-24031. doi: 10.18632/oncotarget.4447

Chen, W. J., Ho, C. C., Chang, Y. L., Chen, H. Y., Lin, C. A., Ling, T. Y., et al. (2014). Cancer-associated fibroblasts regulate the plasticity of lung cancer stemness via paracrine signalling. Nat. Commun. 5:3472. doi: 10.1038/ncomms 4472

Chen, X., Xie, R. H., Gu, P., Huang, M., Han, J. L., Dong, W., et al. (2019). Long noncoding RNA LBCS inhibits self-renewal and chemoresistance of bladder cancer stem cells through epigenetic silencing of SOX2. Clin. Cancer Res. 25, 1389-1403. doi: 10.1158/1078-0432.CCR-181656

Chen, Y. X., Tan, W., and Wang, C. J. (2018). Tumor-associated macrophagederived cytokines enhance cancer stem-like characteristics through epithelialmesenchymal transition. Oncotargets Ther. 11, 3817-3826. doi: 10.2147/OTT. S168317

Chiang, K., Zielinska, A. E., Shaaban, A. M., Sanchez-Bailon, M. P., Jarrold, J., Clarke, T. L., et al. (2017). PRMT5 is a critical regulator of breast cancer stem cell function via histone methylation and FOXP1 expression. Cell Rep. 21, 3498-3513. doi: 10.1016/j.celrep.2017.11.096

Choi, E. J., Seo, E. J., Kim, D. K., Lee, S. I., Kwon, Y. W., Jang, I. H., et al. (2016). FOXP1 functions as an oncogene in promoting cancer stem cell-like characteristics in ovarian cancer cells. Oncotarget 7, 3496-3509. doi: 10.18632/ oncotarget.6510

Cui, J., Wang, Y. Q., Dong, B. J., Qin, L. X., Wang, C., Zhou, P. J., et al. (2018). Pharmacological inhibition of the Notch pathway enhances the efficacy of androgen deprivation therapy for prostate cancer. Int. J. Cancer 143, 645-656. doi: $10.1002 /$ ijc. 31346

Dai, Y. F., Wang, L. J., Tang, J. Q., Cao, P. F., Luo, Z. H., Sun, J., et al. (2016). Activation of anaphase-promoting complex by 553 induces a state of dormancy in cancer cells against chemotherapeutic stress. Oncotarget 7, 25478-25492. doi: 10.18632/oncotarget.8172

Davies, E. J., Marsh, V., and Clarke, A. R. (2011). Origin and maintenance of the intestinal cancer stem cell. Mol. Carcinogen. 50, 254-263. doi: 10.1002/mc. 20631

Dawood, S., Austin, L., and Cristofanilli, M. (2014). Cancer stem cells: implications for cancer therapy. Oncology 28, 1101-1107.

Fang, M., Li, Y. K., Huang, K., Qi, S. S., Zhang, J., Zgodzinski, W., et al. (2017). IL33 promotes colon cancer cell stemness via JNK activation and macrophage recruitment. Cancer Res. 77, 2735-2745. doi: 10.1158/0008-5472.CAN-161602

Fang, Y. X., Chang, Y. L., and Gao, W. Q. (2015). MicroRNAs targeting prostate cancer stem cells. Exp. Biol. Med. 240, 1071-1078. doi: 10.1177/ 1535370215584935

Fessler, E., Borovski, T., and Medema, J. P. (2015). Endothelial cells induce cancer stem cell features in differentiated glioblastoma cells via bFGF. Mol. Cancer 14:157. doi: 10.1186/s12943-015-0420-3

Fiori, M. E., Di Franco, S., Villanova, L., Bianca, P., Stassi, G., and De Maria, R. (2019). Cancer-associated fibroblasts as abettors of tumor progression at the crossroads of EMT and therapy resistance. Mol. Cancer 18:70. doi: 10.1186/ s12943-019-0994-2

Fukusumi, T., Ishii, H., Konno, M., Yasui, T., Nakahara, S., Takenaka, Y., et al. (2014). CD10 as a novel marker of therapeutic resistance and cancer stem cells in head and neck squamous cell carcinoma. Br. J. Cancer 111, 506-514. doi: 10.1038/bjc.2014.289

Hasegawa, T., Yashiro, M., Nishii, T., Matsuoka, J., Fuyuhiro, Y., Morisaki, T., et al. (2014). Cancer-associated fibroblasts might sustain the stemness of scirrhous gastric cancer cells via transforming growth factor-beta signaling. Int. J. Cancer 134, 1785-1795. doi: 10.1002/ijc.28520

Hashimoto, O., Yoshida, M., Koma, Y. I., Yanai, T., Hasegawa, D., Kosaka, Y., et al. (2016). Collaboration of cancer-associated fibroblasts and tumour-associated macrophages for neuroblastoma development. J. Pathol. 240, 211-223. doi: 10.1002/path.4769

Horton, S. J., Giotopoulos, G., Yun, H. Y., Vohra, S., Sheppard, O., BashfordRogers, R., et al. (2017). Early loss of Crebbp confers malignant stem cell properties on lymphoid progenitors. Nat. Cell Biol. 19, 1093-1104. doi: 10.1038/ ncb3597

Hu, Z. H., Cai, M. B., Zhang, Y., Tao, L. L., and Guo, R. X. (2020). miR-29c$3 \mathrm{p}$ inhibits autophagy and cisplatin resistance in ovarian cancer by regulating
FOXP1/ATG14 pathway. Cell Cycle 19, 193-206. doi: 10.1080/15384101.2019. 1704537

Hua, F., Shang, S., Yang, Y. W., Zhang, H. Z., Xu, T. L., Yu, J. J., et al. (2019). TRIB3 interacts with beta-catenin and TCF4 to increase stem cell features of colorectal cancer stem cells and tumorigenesis. Gastroenterology 156, 708-721. doi: 10.1053/j.gastro.2018.10.031

Jin, Y. H., Jiang, Z., Guan, X., Chen, Y. G., Tang, Q. C., Wang, G. Y., et al. (2016). miR-450b-5p suppresses stemness and the development of chemoresistance by targeting SOX2 in colorectal cancer. DNA Cell Biol. 35, 249-256. doi: 10.1089/ dna. 2015.3120

Jo, H., Jia, Y. H., Subramanian, K. K., Hattori, H., and Luo, H. B. R. (2008). Cancer cell-derived clusterin modulates the phosphatidylinositol 3'-kinase-Akt pathway through attenuation of insulin-like growth factor 1 during serum deprivation. Mol. Cell Biol. 28, 4285-4299. doi: 10.1128/MCB.01240-07

Kesh, K., Gupta, V. K., Durden, B., Garrido, V., Mateo-Victoriano, B., Lavania, S. P., et al. (2020). Therapy resistance, cancer stem cells and ECM in cancer: the matrix reloaded. Cancers 12:3067. doi: 10.3390/cancers121 03067

Kim, J. H., Choi, H. S., Kim, S. L., and Lee, D. S. (2019). The PAK1-Stat3 signaling pathway activates IL-6 gene transcription and human breast cancer stem cell formation. Cancers 11:1527. doi: 10.3390/cancers11101527

Kinugasa, Y., Matsui, T., and Takakura, N. (2014). CD44 expressed on cancerassociated fibroblasts is a functional molecule supporting the Stemness and drug resistance of malignant cancer cells in the tumor microenvironment. Stem Cells 32, 145-156. doi: 10.1002/stem.1556

Kleffel, S., and Schatton, T. (2013). Tumor dormancy and cancer stem cells: two sides of the same coin? Adv. Exp. Med. Biol. 734, 145-179. doi: 10.1007/978-14614-1445-2_8

Krishnamurthy, S., Dong, Z. H., Vodopyanov, D., Imai, A., Helman, J. I., Prince, M. E., et al. (2010). Endothelial cell-initiated signaling promotes the survival and self-renewal of cancer stem cells. Cancer Res. 70, 9969-9978. doi: 10.1158/ 0008-5472.CAN-10-1712

Lau, E. Y. T., Lo, J., Cheng, B. Y. L., Ma, M. K. F., Lee, J. M. F., Ng, J. K. Y., et al. (2016). Cancer-associated fibroblasts regulate tumor-initiating cell plasticity in hepatocellular carcinoma through c-Met/FRA1/HEY1 signaling. Cell Rep. 15, 1175-1189. doi: 10.1016/j.celrep.2016.04.019

Li, D. Q., Nair, S. S., Ohshiro, K., Kumar, A., Nair, V. S., Pakala, S. B., et al. (2012). MORC2 signaling integrates phosphorylation-dependent, ATPasecoupled chromatin remodeling during the DNA damage response. Cell Rep. 2 , 1657-1669. doi: 10.1016/j.celrep.2012.11.018

Li, J., Yu, B., Deng, P., Cheng, Y. D., Yu, Y. X., Kevork, K., et al. (2017). KDM3 epigenetically controls tumorigenic potentials of human colorectal cancer stem cells through Wnt/beta-catenin signalling. Nat. Commun. 8:15146. doi: 10. 1038/ncomms 15146

Li, S. L., Yue, D. L., Chen, X. F., Wang, L. P., Li, J. Y., Ping, Y., et al. (2015). Epigenetic regulation of CD271, a potential cancer stem cell marker associated with chemoresistance and metastatic capacity. Oncol. Rep. 33, 425-432. doi: 10.3892/or.2014.3569

Li, S. X., Han, Z. P., Zhao, N. P., Zhu, B., Zhang, Q. W., Yang, X., et al. (2018). Inhibition of DNMT suppresses the stemness of colorectal cancer cells through down-regulating Wnt signaling pathway. Cell Signal. 47, 79-87. doi: 10.1016/j. cellsig.2018.03.014

Liao, C. P., Chen, L. Y., Luethy, A., Kim, Y., Kani, K., MacLeod, A. R., et al. (2017). Androgen receptor in cancer-associated fibroblasts influences stemness in cancer cells. Endocr. Relat. Cancer 24, 157-170. doi: 10.1530/ERC-16-0138

Liau, B. B., Sievers, C., Donohue, L. K., Gillespie, S. M., Flavahan, W. A., Miller, T. E., et al. (2017). Adaptive chromatin remodeling drives glioblastoma stem cell plasticity and drug tolerance. Cell Stem Cell 20, 233-246. doi: 10.1016/j. stem.2016.11.003

Liu, K., Lee, J., Kim, J. Y., Wang, L. Y., Tian, Y. J., Chan, S. T., et al. (2017). Mitophagy controls the activities of tumor suppressor p53 to regulate hepatic cancer stem cells. Mol. Cell 68, 281-292. doi: 10.1016/j.molcel.2017.09.022

Liu, Y. P., Yang, C. J., Huang, M. S., Yeh, C. T., Wu, A. T. H., Lee, Y. C., et al. (2013). Cisplatin selects for multidrug-resistant CD133(+) cells in lung adenocarcinoma by activating notch signaling. Cancer Res. 73, 406-416. doi: 10.1158/0008-5472.CAN-12-1733

Lv, C., Li, F. Y., Li, X., Tian, Y. H., Zhang, Y., Sheng, X. L., et al. (2017). MiR-31 promotes mammary stem cell expansion and breast tumorigenesis by 
suppressing Wnt signaling antagonists. Nat. Commun. 8:1036. doi: 10.1038/ s41467-017-01059-5

Ma, Q. Q., Long, W. Y., Xing, C. S., Jiang, C. M., Su, J., Wang, H. Y., et al. (2020). PHF20 promotes glioblastoma cell malignancies through a WISP1/BGNdependent pathway. Front. Oncol. 10:573318. doi: 10.3389/fonc.2020.573318

Matsui, W. H. (2016). . Cancer stem cell signaling pathways. Medicine 95(1 Suppl. 1), S8-S19. doi: 10.1097/MD.0000000000004765

Mens, M. M. J., and Ghanbari, M. (2018). Cell cycle regulation of stem cells by MicroRNAs. Stem Cell Rev. Rep. 14, 309-322. doi: 10.1007/s12015-018-9808-y

Mitchem, J. B., Brennan, D. J., Knolhoff, B. L., Belt, B. A., Zhu, Y., Sanford, D. E., et al. (2013). Targeting tumor-infiltrating macrophages decreases tumorinitiating cells, relieves immunosuppression, and improves chemotherapeutic responses. Cancer Res. 73, 1128-1141. doi: 10.1158/0008-5472.CAN-12-2731

Miyazaki, Y., Matsubara, S., Ding, Q., Tsukasa, K., Yoshimitsu, M., Kosai, K., et al. (2016). Efficient elimination of pancreatic cancer stem cells by hedgehog/GLI inhibitor GANT61 in combination with mTOR inhibition. Mol. Cancer 15:49. doi: 10.1186/s12943-016-0534-2

Nasr, M. A., Salah, R. A., Abd Elkodous, M., Elshenawy, S. E., and El-Badri, N. (2019). Dysregulated MicroRNA fingerprints and methylation patterns in hepatocellular carcinoma, cancer stem cells, and mesenchymal stem cells. Front. Cell Dev. Biol. 7:229. doi: 10.3389/fonc.2020.000229

Norollahi, S. E., Mansour-Ghanaei, F., Joukar, F., Ghadarjani, S., Mojtahedi, K., Nejad, K. G., et al. (2019). Therapeutic approach of Cancer stem cells (CSCs) in gastric adenocarcinoma; DNA methyltransferases enzymes in cancer targeted therapy. Biomed. Pharmacother. 115:108958. doi: 10.1016/j.biopha. 2019.108958

O’Brien, C. A., Pollett, A., Gallinger, S., and Dick, J. E. (2007). A human colon cancer cell capable of initiating tumour growth in immunodeficient mice. Nature 445, 106-110. doi: 10.1038/nature05372

Park, N. I., Guilhamon, P., Desai, K., McAdam, R. F., Langille, E., O’Connor, M., et al. (2017). ASCL1 reorganizes chromatin to direct neuronal fate and suppress tumorigenicity of glioblastoma stem cells. Cell Stem Cell 21, 209-224. doi: 10.1016/j.stem.2017.06.004

Ren, J., Ding, L., Zhang, D., Shi, J., Xu, Q., Shen, S., et al. (2018). Carcinomaassociated fibroblasts promote the stemness and chemoresistance of colorectal cancer by transferring exosomal lncRNA H19. Theranostics 8, 3932-3948. doi: 10.7150/thno. 25541

Rheinbay, E., Suva, M. L., Gillespie, S. M., Wakimoto, H., Patel, A. P., Shahid, M., et al. (2013). An aberrant transcription factor network essential for Wnt signaling and stem cell maintenance in glioblastoma. Cell Rep. 3, 1567-1579. doi: 10.1016/j.celrep.2013.04.021

Sainz, B., Carron, E., Vallespinos, M., and Machado, H. L. (2016). Cancer stem cells and macrophages: implications in tumor biology and therapeutic strategies. Mediat. Inflamm. 2016:9012369. doi: 10.1155/2016/9012369

Samadani, A. A., and Akhavan-Niaki, H. (2015). Interaction of sonic hedgehog (SHH) pathway with cancer stem cell genes in gastric cancer. Med. Oncol. 32:48. doi: 10.1007/s12032-015-0492-3

Schwitalla, S., Fingerle, A. A., Cammareri, P., Nebelsiek, T., Goktuna, S. I., Ziegler, P. K., et al. (2013). Intestinal tumorigenesis initiated by dedifferentiation and acquisition of stem-cell-like properties. Cell 152, 25-38. doi: 10.1016/j.cell.2012. 12.012

Shah, M., Cardenas, R., Wang, B., Persson, J., Mongan, N. P., Grabowska, A., et al. (2017). HOXC8 regulates self-renewal, differentiation and transformation of breast cancer stem cells. Mol. Cancer 16:38. doi: 10.1186/s12943-0170605-Z

Shimono, Y., Zabala, M., Cho, R. W., Lobo, N., Dalerba, P., Qian, D. L., et al. (2009). Downregulation of miRNA-200c links breast cancer stem cells with normal stem cells. Cell 138, 592-603. doi: 10.1016/j.cell.2009.07.011

Skvortsov, S., Debbage, P., Lukas, P., and Skvortsova, I. (2015). Crosstalk between DNA repair and cancer stem cell (CSC) associated intracellular pathways. Semin. Cancer Biol. 31, 36-42. doi: 10.1016/j.semcancer.2014.06.002

Skvortsova, I., Debbage, P., Kumar, V., and Slwortsov, S. (2015). Radiation resistance: cancer stem cells (CSCs) and their enigmatic pro-survival signaling. Semin. Cancer Biol. 35, 39-44. doi: 10.1016/j.semcancer.2015.09.009

Somasagara, R. R., Spencer, S. M., Tripathi, K., Clark, D. W., Mani, C., da Silva, L. M., et al. (2017). RAD6 promotes DNA repair and stem cell signaling in ovarian cancer and is a promising therapeutic target to prevent and treat acquired chemoresistance. Oncogene 36, 6680-6690. doi: 10.1038/onc.2017.279
Stefansson, O. A., and Esteller, M. (2011). EZH2-mediated epigenetic repression of DNA repair in promoting breast tumor initiating cells. Breast Cancer Res. 13:309. doi: $10.1186 /$ bcr2871

Su, S. C., Chen, J. N., Yao, H. R., Liu, J., Yu, S. B., Lao, L. Y., et al. (2018). CD10(+) GPR77(+) cancer-associated fibroblasts promote cancer formation and chemoresistance by sustaining cancer stemness. Cell 172, 841-856. doi: 10.1016/j.cell.2018.01.009

Suva, M. L., Riggi, N., Janiszewska, M., Radovanovic, I., Provero, P., Stehle, J. C., et al. (2009). EZH2 is essential for glioblastoma cancer stem cell maintenance. Cancer Res. 69, 9211-9218. doi: 10.1158/0008-5472.CAN-09-1622

Toh, T. B., Lim, J. J., and Chow, E. K. H. (2017). Epigenetics in cancer stem cells. Mol. Cancer 16:29. doi: 10.1186/s12943-017-0596-9

van Vlerken, L. E., Kiefer, C. M., Morehouse, C., Li, Y., Groves, C., Wilson, S. D., et al. (2013). EZH2 is required for breast and pancreatic cancer stem cell maintenance and can be used as a functional cancer stem cell reporter. Stem Cell Transl. Med. 2, 43-52. doi: 10.5966/sctm.2012-0036

Vidovic, D., Huynh, T. T., Konda, P., Dean, C., Cruickshank, B. M., Sultan, M., et al. (2020). ALDH1A3-regulated long non-coding RNA NRAD1 is a potential novel target for triple-negative breast tumors and cancer stem cells. Cell Death Differ. 27, 363-378. doi: 10.1038/s41418-019-0362-1

Visvader, J. E., and Lindeman, G. J. (2012). Cancer stem cells: current status and evolving complexities. Cell Stem Cell 10, 717-728. doi: 10.1016/j.stem.2012. 05.007

Wan, S. S., Zhao, E. D., Kryczek, I., Vatan, L., Sadovskaya, A., Ludema, G., et al. (2014). tumor-associated macrophages produce interleukin 6 and signal via STAT3 to promote expansion of human hepatocellular carcinoma stem cells. Gastroenterology 147, 1393-1404. doi: 10.1053/j.gastro.2014. 08.039

Wang, G. L., Song, Y. Y., Liu, T., Wang, C. Y., Zhang, Q., Liu, F. R., et al. (2015). PAK1-mediated MORC2 phosphorylation promotes gastric tumorigenesis. Oncotarget 6, 9877-9886. doi: 10.18632/oncotarget.3185

Wang, J., Zhu, H. H., Chu, M. L., Liu, Y. Y., Zhang, C. X., Liu, G., et al. (2014). Symmetrical and asymmetrical division analysis provides evidence for a hierarchy of prostate epithelial cell lineages. Nat. Commun. 5:4758. doi: 10.1038/ncomms5758

Wang, K., Zhang, T., Dong, Q., Nice, E. C., Huang, C. H., and Wei, Y. Q. (2013). Redox homeostasis: the linchpin in stem cell self-renewal and differentiation. Cell Death Dis. 4:e537. doi: 10.1038/cddis.2013.50

Wang, R., Bhattacharya, R., Ye, X. C., Fan, F., Boulbes, D. R., Xia, L., et al. (2017). Endothelial cells activate the cancer stem cell-associated NANOGP8 pathway in colorectal cancer cells in a paracrine fashion. Mol. Oncol. 11, 1023-1034. doi: 10.1002/1878-0261.12071

Wang, X., Xu, H. B., Cheng, C. P., Ji, Z. Z., Zhao, H. F., Sheng, Y. R., et al. (2020). Identification of a Zebl expressing basal stem cell subpopulation in the prostate. Nat. Commun. 11:706. doi: 10.1038/s41467-020-14296-y

Wang, Y., He, L., Du, Y., Zhu, P., Huang, G., Luo, J., et al. (2015). The long noncoding RNA lncTCF7 promotes self-renewal of human liver cancer stem cells through activation of Wnt signaling. Cell Stem Cell 16, 413-425. doi: 10.1016/j.stem.2015.03.003

Wang, Z. S., Yang, P., Xie, J., Lin, H. P., Kumagai, K., Harkema, J., et al. (2020). Arsenic and benzo[a]pyrene co-exposure acts synergistically in inducing cancer stem cell-like property and tumorigenesis by epigenetically down-regulating SOCS3 expression. Environ. Int. 137:105560. doi: 10.1016/j.envint.2020.105560

Wen, Y. P., Cai, J., Hou, Y. Y., Huang, Z. J., and Wang, Z. H. (2017). Role of EZH2 in cancer stem cells: from biological insight to a therapeutic target. Oncotarget 8, 37974-37990. doi: 10.18632/oncotarget.16467

Xiao, W., Gao, Z., Duan, Y., Yuan, W., and Ke, Y. (2017). Notch signaling plays a crucial role in cancer stem-like cells maintaining stemness and mediating chemotaxis in renal cell carcinoma. J. Exp. Clin. Cancer Res. 36:41. doi: 10. 1186/s13046-017-0507-3

Xu, L. Y., Hou, Y. X., Tu, G., Chen, Y. L., Du, Y. E., Zhang, H. L., et al. (2017). Nuclear Drosha enhances cell invasion via an EGFR-ERK1/2-MMP7 signaling pathway induced by dysregulated miRNA-622/197 and their targets LAMC2 and CD82 in gastric cancer. Cell Death Dis. 8:e2642. doi: 10.1038/cddis. 2017.5

Yan, D. J., Yan, X. J., Dai, X. F., Chen, L. X., Sun, L. B., Li, T., et al. (2019). Activation of AKT/AP1/FoxM1 signaling confers sorafenib resistance to liver cancer cells. Oncol. Rep. 42, 785-796. doi: 10.3892/or.2019.7192 
Yan, X. L., Liu, X. H., Wang, Z. H., Cheng, Q., Ji, G. H., Yang, H., et al. (2019). MicroRNA-486-5p functions as a tumor suppressor of proliferation and cancer stem-like cell properties by targeting Sirt1 in liver cancer. Oncol. Rep. 41, 1938-1948. doi: 10.3892/or.2018.6930

Yang, J., Liao, D. B., Chen, C., Liu, Y., Chuang, T. H., Xiang, R., et al. (2013). Tumor-associated macrophages regulate murine breast cancer stem cells through a novel paracrine EGFR/Stat3/Sox-2 signaling pathway. Stem Cells 31, 248-258. doi: 10.1002/stem.1281

Yasuda, K., Torigoe, T., Mariya, T., Asano, T., Kuroda, T., Matsuzaki, J., et al. (2014). Fibroblasts induce expression of FGF4 in ovarian cancer stem-like cells/cancer-initiating cells and upregulate their tumor initiation capacity. Lab. Invest. 94, 1355-1369. doi: 10.1038/labinvest.2014.122

Yu, B. B., Wu, K. L., Wang, X., Zhang, J. J., Wang, L. Z., Jiang, Y. Y., et al. (2018). Periostin secreted by cancer-associated fibroblasts promotes cancer stemness in head and neck cancer by activating protein tyrosine kinase 7. Cell Death Dis. 9:1082. doi: 10.1038/s41419-018-1116-6

Yu, F., Deng, H., Yao, H., Liu, Q., Su, F., and Song, E. (2010). Mir-30 reduction maintains self-renewal and inhibits apoptosis in breast tumor-initiating cells. Oncogene 29, 4194-4204. doi: 10.1038/onc.2010.167

Zhang, H. L., Hou, Y. X., Xu, L. Y., Zeng, Z. Y., Wen, S. Y., Du, Y. E., et al. (2016). Cytoplasmic Drosha is aberrant in precancerous lesions of gastric carcinoma and its loss predicts worse outcome for gastric cancer patients. Digest. Dis. Sci. 61, 1080-1090. doi: 10.1007/s10620-015-3986-0

Zhang, K., Guo, Y. J., Wang, X., Zhao, H. F., Ji, Z. Z., Cheng, C. P., et al. (2017). WNT/beta-Catenin directs self-renewal symmetric cell division of hTERT(high) prostate cancer stem cells. Cancer Res. 77, 2534-2547. doi: 10. 1158/0008-5472.CAN-16-1887

Zhang, S. C., Zhao, B. S., Zhou, A. D., Lin, K. Y., Zheng, S. P., Lu, Z. K., et al. (2017). m(6)A Demethylase ALKBH5 maintains tumorigenicity of glioblastoma stem-like cells by sustaining FOXM1 expression and cell proliferation program. Cancer Cell 31, 591-606. doi: 10.1016/j.ccell.2017. 02.013

Zhao, M. J., Hou, Y. X., Du, Y. E., Yang, L. P., Qin, Y. L., Peng, M. X., et al. (2020). Drosha-independent miR-6778-5p strengthens gastric cancer stem cell stemness via regulation of cytosolic one-carbon folate metabolism. Cancer Lett. 478, 8-21. doi: 10.1016/j.canlet.2020.02.040

Zhou, P. J., Wang, X., An, N., Wei, L. Z., Zhang, L., Huang, X. X., et al. (2019). Loss of Par3 promotes prostatic tumorigenesis by enhancing cell growth and changing cell division modes. Oncogene 38, 2192-2205. doi: 10.1038/s41388018-0580-x

Zhu, P. P., Wang, Y. Y., Huang, G. L., Ye, B. Q., Liu, B. Y., Wu, J. Y., et al. (2016). Lnc-beta-Catm elicits EZH2-dependent beta-catenin stabilization and sustains liver CSC self-renewal. Nat. Struct. Mol. Biol. 23, 631-639. doi: 10.1038/nsmb. 3235

Zhu, R., and Wang, H. (2020). TSPAN8 promotes cancer cell Stemness via activation of sonic hedgehog signaling. Pancreas 49, 155-155. doi: 10.1038/ s41467-019-10739-3

Conflict of Interest: The authors declare that the research was conducted in the absence of any commercial or financial relationships that could be construed as a potential conflict of interest.

Copyright (C) 2021 Jing, Gao and Fang. This is an open-access article distributed under the terms of the Creative Commons Attribution License (CC BY). The use, distribution or reproduction in other forums is permitted, provided the original author(s) and the copyright owner(s) are credited and that the original publication in this journal is cited, in accordance with accepted academic practice. No use, distribution or reproduction is permitted which does not comply with these terms. 